\title{
PROCEE: a PROstate cancer evaluation and education serious game for African Caribbean men
}

Georgina Cosma, David Brown, Nicholas Shopland, Steven Battersby, Sarah Seymour-Smith, Matthew Archer, Masood Khan and A. Graham Pockley

\begin{abstract}
Purpose - Prostate cancer is the most common cancer diagnosed in men in the UK. Black men are in a higher prostate cancer risk group possibly due to inherent genetic factors. The purpose of this paper is to introduce PROstate Cancer Evaluation and Education (PROCEE), an innovative serious game aimed at providing prostate cancer information and risk evaluation to black African-Caribbean men.

Design/methodology/approach - PROCEE has been carefully co-designed with prostate cancer experts, prostate cancer patients and members of the black African-Caribbean community in order to ensure that it meets the real needs and expectations of the target audience.

Findings - During the co-design process, the users defined an easy to use and entertaining game which can effectively raise awareness, inform users about prostate cancer and their risk, and encourage symptomatic men to seek medical attention in a timely manner.

Originality/value - During focus group evaluations, users embraced the game and emphasised that it can potentially have a positive impact on changing user behaviour among high risk men who are experiencing symptoms and who are reluctant to visit their doctor.
\end{abstract}

1. Introduction

Black men and men with a family history of prostate cancer are in the higher risk group (Burford et al., 2009; Ream et al., 2010), possibly due to inherent genetic factors (Bunker et al., 2002; Center et al., 2012; Glover et al., 1998; Siegel et al., 2011). Several barrierslimitAfrican-Caribbean men from seeking advice for prostate cancer. These barriers include unawareness of risk, symptoms and treatments for prostate cancer, trust/mistrust of healthcare services and fear of screening (Ream et al., 2010). When experiencing symptoms, these barriers may hinder prompt medical assessment, impairing the effectiveness of treatment, which in turn couldaffectmorbidity and mortality (Heijnsdijk et al., 2012; Luján et al., 2012; Schröder et al., 2012). Early presentation can save lives, and for this reason targeted interventions that are ableto effectively combat these barriers and encourage early screening in order to reduce the risk of mortality are required (Heijnsdijk et al., 2012; Luján et al., 2012; Ream et al., 2010; Schröder et al., 2012).

Serious games are computer games which are developed for purposes other than just entertainment. Serious games which are designed for health purposes can be used to educate 
andtrain patientsandhealthcareprofessionals(Wattanasoontornetal.,2013).Studieshaveshown that carefully designed games can havea positive impacton the health behaviour of young people and those with cancer, and that games can be used for effective disease management and disease-related knowledge (Davis et al., 2004; Kato et al., 2008; Reichlin et al., 2011b). Some serious games have been devised to improve the health of players and other games have been developed for helping users manage their disease(Thompson et al., 2008). For example, serious gameshave been designedfor motor rehabilitationand treating patients with chroniclower backor neck pain (Schönauer et al., 2011), and to improve motor functions within stroke patients (Saposnik et al., 2010). Serious games have also been created to combat obesity using multiple approaches including physical exercise, self-control and monitoring, consuming health food and decreasing daily intake of food (Alamri et al., 2014). Serious games have been developed for promoting the prevention and awareness of type 2 diabetes and obesity (Thompson et al., 2008); for informing primary carephysicians of how much insulina patient with diabetes needs (Diehl et al., 2013); and for teaching teenagers self-management of diabetes mellitus type 1 (Fuchslocher et al., 2011). Other games have been developed to teach children about asthma and to help them manage it (Lieberman, 2001). With regards to prostate cancer, TimeAfter Time is a serious game which has been specifically designed to aid men with localised prostate cancer to choose one of the potentially life-altering treatments. The game is evaluated by Reichlin et al. (2011a) who found that during studies on the gamethemajority of participants believed the game acted as a valuablestep towards making a decision. It is also reported that improvements can still be made on the game to allow patients to match their expectations with their realistic goals.

The development of culturally appropriate interventions which are capable of effectively enhancing knowledge and understanding of prostate cancer in African-Caribbean men requires the involvement of the community in the design and development process, and this is can be achieved by co-design. The PROstate Cancer Evaluation and Education (PROCEE) serious game which is discussed in this paper, provides users with prostate cancer information and evaluates their risk based on their profile. Each user receives personalised feedback based on their responses that are gathered while using the game. The integrated expert system layer within PROCEE enables the evaluation of each user's risk of prostate cancer and adjusts the content in such a way that it persuades symptomatic men to seek medical advice. The content of the game has been co-designed with experts and the community in order to take into consideration the African-Caribbean men's perceptions of prostate cancer, risk factors, medical tests and concerns, and to ensure that it is designed to purpose.

This paper is structured as follows: Section 2 describes the co-design methodology used for the design of the PROCEE serious game; Section 3 discusses the framework of the PROCEE serious game; Section 4 discusses the software development methodology applied to design and develop the serious game; Section 5 discusses the feedback obtained from evaluations of the serious game; and Section 6 provides the conclusions and future work.

\section{The co-design methodology of the PROCEE serious game}

Co-design isthe process of creating design interventions withrepresentative participants of the target group. Intypical entertainmentorientated games, the player is usually only consulted when a playable version of the game has been developed, and is rarely contacted before that stage (Khaled, 2012). Thiscanresultinminimal player involvementduringtheconceptual stage(Winn, 2008). Morerecently, the design process for games is changing, with entertainment game designers investigating and testing techniques which involve a collaboration with the players during the design phase (Lange-Nielsen et al., 2012). This allows for the knowledge gap to be closed between the players and the game designers and, as a result, a rapidly growing number of serious game designers are exploring different ways to involve the player in design (Danielsson and Wiberg, 2006). For a number of reasons, co-design with end-users is becoming more valued by technology designers. It is argued thatco-design increases publicengagementwith theresearch, whilstfacilitating learning and change. Possibly the most important reason for using co-design when designing a game is to ensure that the technologies are aligned to what the game requires and people's needs, along with removing designer subjectivity (Vines et al., 2013). When designing a serious game, many factors need to be taken into account in order to effectively employ the medium's entertaining and engaging format. 
The design team should include entertainment (i.e. game artists, writers, designers and software programmers) and behaviour change (i.e. behavioural scientists and content specialists) experts in order to deploy media in their optimum format (Stokes, 2005; Thompson et al., 2008). When interacting with the gamethe player must abide by the rules of the game. These rules, along with the game model, present the player with possible pre-defined actions to take. Monitoring the player's actions helps define the assessment rules, and a log of the actions can be utilised to assess the player's activities and performance within the game (Al-Smadi et al., 2012).

The co-design process of the PROCEE serious game, follows the Serious Game Design Assessment (SGDA) framework proposed by Mitgutsch and Alvarado (2012), as illustrated in Figure 1. The SGDA is a suitable framework, as it allows for the design elements to beconfigured "formally and conceptually in relation to the game's aim and purpose"Mitgutsch and Alvarado (2012). Below, is a description of how the SGDA components have been utilised to co-design the PROCEE serious game:

1. Purpose: the purpose of the PROCEE serious game is to raise awareness of prostate cancer among symptomatic and asymptomatic men; to inform men about prostate cancer risk factors and symptoms; to evaluate symptoms; and to encourage symptomatic men to consult their doctors. The game's intention is to make people aware of prostate cancer risks and symptoms while they are having fun playing the game; to engagethem in understanding the reasons for which they are in a high risk group; to increase their vigilance towards recognising the symptoms of prostate cancer; and to alleviate the concerns related to prostate cancer testing. Hence, for the game to be successful it must impact:

- onthe behaviour of thosemen who experiencesymptomsand whoarereluctantto seetheir doctor. Encourage symptomatic men to visit their family doctor/general practitioner; and

- educate men about prostate cancer risks and symptoms via concise information using the correct message framing and level of detail.

Figure 1 Serious game design assessment framework

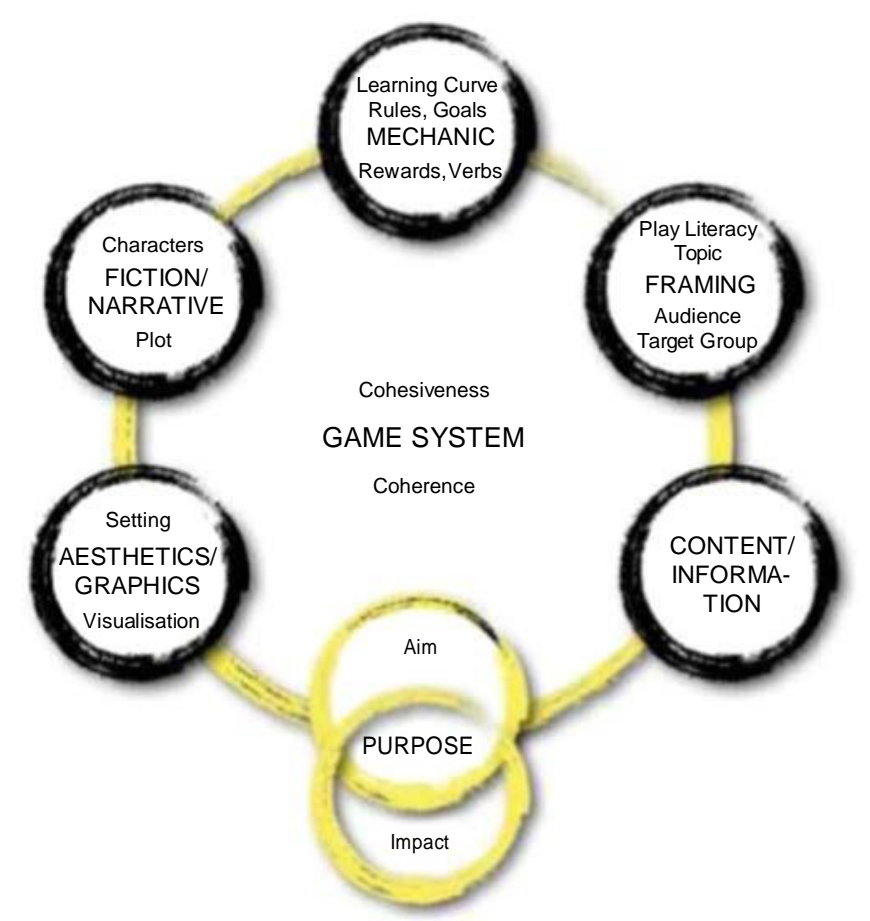

Source: Mitgutsch and Alvarado (2012) 
2. Settingaestheticsgraphics/visualisation:agraphicsdesignerproduced thecharacters of the game. The graphics designer worked in close collaboration with the community members in order to produce appropriate characters for the game. The characters that were produced, arewell known to the community and henceto the targetpopulation. Such a character, Patty Dumplin, is presented in Figure 2, and is well known and embraced by the African-Caribbean community.

3. Fiction/narrative: ideas on the narrative were discussed with community members who proposed and considered several fictional scenarios. After much consideration they decided on the most preferred theme and fictional scenario, and also provided the setting and narrative of the serious game. Thenarrative wasthen given to a well-knownactor/director of the black African-Caribbean community, who adjusted the content in order to emphasise messages and to add appropriate humour into the narrative. The actor/director also collaborated with the graphic designer to ensure a match between the images and the characters described in the narrative.

4. Mechanic: the decision logic behind the serious game feedback was developed by a group of prostatecancer expertsmakingthisa rule-based system. Initially, user requirementswere gathered and experts provided knowledge and facts which were used to create the rules for the logic behind the serious game (questions and possible answers). Expert rules were devised which were then used to generate paths and feedback provided to the user.

5. Framing: in order for the gameto enhance the user's understanding of prostate cancer risks, and to encourage symptomatic users to visit seek medical help, the content of the game must be appropriately messaged. Appropriate message framing was applied within the game to highlight the advantages of visiting a doctor when they experience symptoms and thenegativeeffects of ignoring symptoms. Inorder toensurethatmessages were effectively constructed, a psychologist, prostate cancer experts, the actor/director and community members were involved in the task of appropriately framing the messages such that they have an impact on user behaviour.

6. Content information: the content of the game was carefully developed by researchers and prostate cancer experts. The narrative was voice recorded by theactor/director in Jamaican Patois, also called Jamaican Creole by linguists. Jamaican patois is an English-based creole language with West African influences spoken primarily in Jamaica and the Jamaican diaspora. Subtitles were also added in standard British English for non-Jamaican players.

Figure 2 Known African-Caribbean character: Patty Dumplin

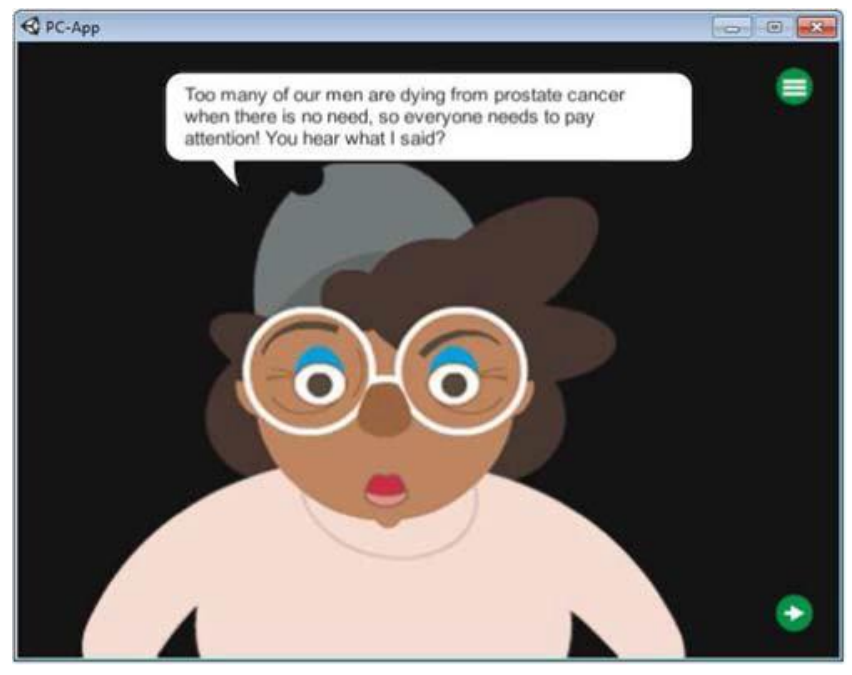




\section{The PROCEE serious game framework}

The aim of the serious game is to raise awareness, evaluate the prostate cancer risk of users and provide personalised information to users. The overall architecture of the serious game is illustrated in Figure 3. The game's levels resulted from co-designing the system using the Agile-SGDA methodology, as discussed in Section 2. The levels of the game are described below:

1. Gameintroduction: upon starting the game for the first time, the user enters the introduction (barbersaloon) level. Whilstplayingthegame, theuserisintroduced tothethemeina friendly and interactive way. Below are some basic facts about the game:

- game setting: at a barber salon;

- player character: client;

- non-player characters: barber, other characters visiting the barber shop;

- target audience: 25-70;

- number of levels: 8; and

- time needed to complete from start to finish: 10-15 minutes.

2. Prostate cancer risks level: the user (i.e. customer at the barber shop) is in conversation with the "non-player characters" (i.e. mainly the barber) and is provided with information via friendly conversations. The flow of the conversation changes based on the user's responses. The aim of this level is to inform users about prostate cancer and its risks.

Figure 3 PROCEE serious game framework

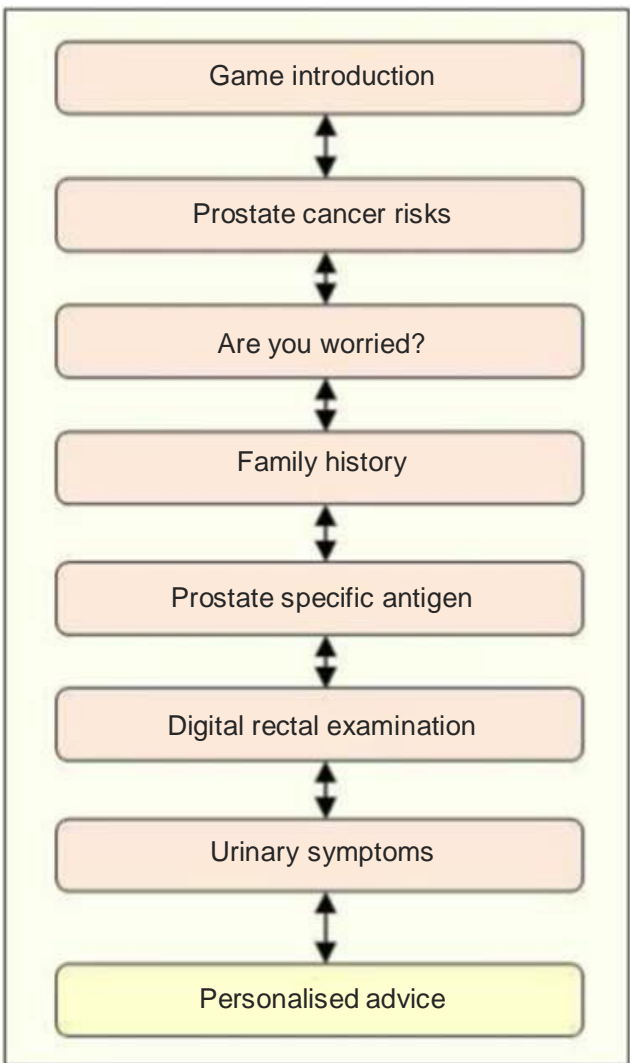


3. Are you worried? level: while playing this level, the user is asked whether $s /$ he is worried about prostate cancer and these worries are discussed with non-player characters. The responses of the user are saved and influence the advice (feedback) given to the user.

4. Family history level: in this level the user is asked questions related to his family history. The responses of the user are saved and influence the advice (feedback) given to the user.

5. Prostate specific antigen (PSA) test level: in this level the user is informed about the PSA test and interacts with non-player characters to obtain answers to questions related to the PSA test.

6. Digital rectal examination (DRE) level: in this level the user is informed about the DRE and interacts with non-player characters to obtain answers to DRE related questions.

7. Urinary symptoms level: the urinary symptoms level asks the user a set of questions taken and adapted from the International Prostate Symptom Score (IPSS) questionnaire. The result of the IPSS test was used to personalise the advice provided to the user. The IPSS questions assess urinary problems indicative of an enlarged prostate, which could be related to prostate cancer. Each IPSS question allows the user to choose one out of six answers indicating increasing severity of the particular symptom. The answer to each question is assigned a score from 0 to 5 . Only the first seven questions are scored and thereforethetotal score can range from 0 to 35 (asymptomatic to very symptomatic). Question 8 refers to the patient's perceived quality of life and its score is not counted towards the overall IPSS scorethe patient is advised to discuss the outcome of question 8 with their doctor. The first seven questions of the IPSS are similar to the questions appearing on the American Urological Association Symptom Index which currently categorises symptoms as mild, moderate or severe based on the user's score. The questions found in the IPSS survey are shown in Table I. Let $i$ be the question number and $N$ is the total number of questions. Each question $i$ can be assigned a score, such that score $i \in\{0, \ldots, 5\}$. The IPSS score of a user is computed via the summation of all his scores such that:

$$
\text { IPSS Score }=\sum_{i=1}^{N} \text { score }_{i}
$$

The IPSS Score indicates the severity of symptoms, as follows:

IF userScore $<=7$ THEN

SYMPTOMS=MILD

IF userScore $>7$ AND userScore $<=19$ THEN

SYMPTOMS=MODERATE

IF userScore $>19$ AND userScore $<=35$ THEN

SYMPTOMS $=$ SEVERE 
8. Personalised advice: the feedback provided to the user is based on the set of rules provided by experts. Personalised advice is presented based on the results of the user's responses which are stored in the following variables:

- PlayerAge: this variable records the player's age.

- ProstateCancerChecked: this variable stores the user's response to a question on whether he has had his prostate checked. Possible answers include, Yes and No.

- IsConcerned: this variable stores the user's response on whether he is concerned about prostate cancer. Possible answers include, Yes and No.

- BCFamilyHistory: this variable stores the user's response on family history of breast cancer. Possible answers include, Yes, No, and Don't Know.

- PCFamilyHistory: this is family history of prostate cancer. Possible answers include, Yes, No and Don't Know.

- RelativeAgeAtDiagnosis: this is the close relative's age at prostate cancer diagnosis (if known).

- IPSSscore: this is the result of the IPSS questionnaire.

- WillGetChecked: this variable stores the user's response as to whether he will get checked. Possible answers include, Yes and No.

Experts provided knowledge and facts which were used to createthe rules for the logic behind the serious game (questions and possible answers); making this a rule-based system. The expert rules were used todrivethegame flowand generatethe final feedback provided totheuser. Eachlevel is locked until the user completes all activities associated with that level (as illustrated in the state machine diagram in Figure 4). As the user completes each activity, the responses provided by the user are saved, and these responses are used to generate the final feedback provided to the user. Figure 5 illustrates the components of the expert system sitting beneath the serious game.

The user requirements for designing the game were gathered using an Agile based co-design methodology, and these are discussed in Section 4.

\section{Agile-SGDA: a hybrid software development methodology}

Since the aim of the serious game was to impact on user behaviour, it was necessary to involve potential users, patients and experts during all the software development stages - from the requirements gathering to the design and development of the serious game. Although the Agile software development methodology was adopted, it was integrated with the SGDA co-design methodology in order to accommodate the co-design activities (Mitgutsch and Alvarado, 2012).

Figure 4 State machine diagram showing the transition between the states of a level

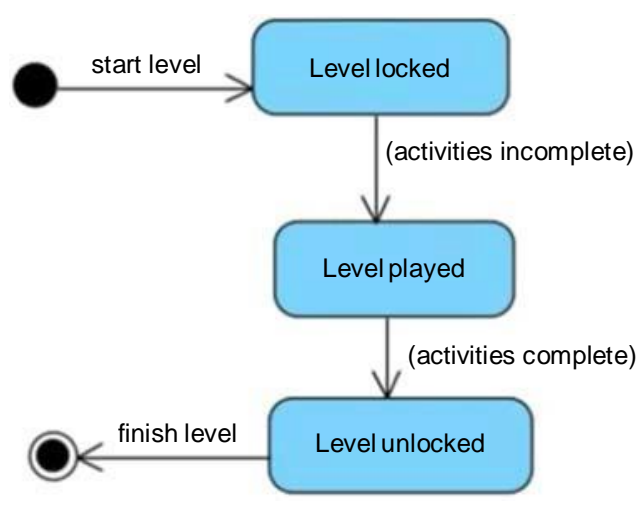




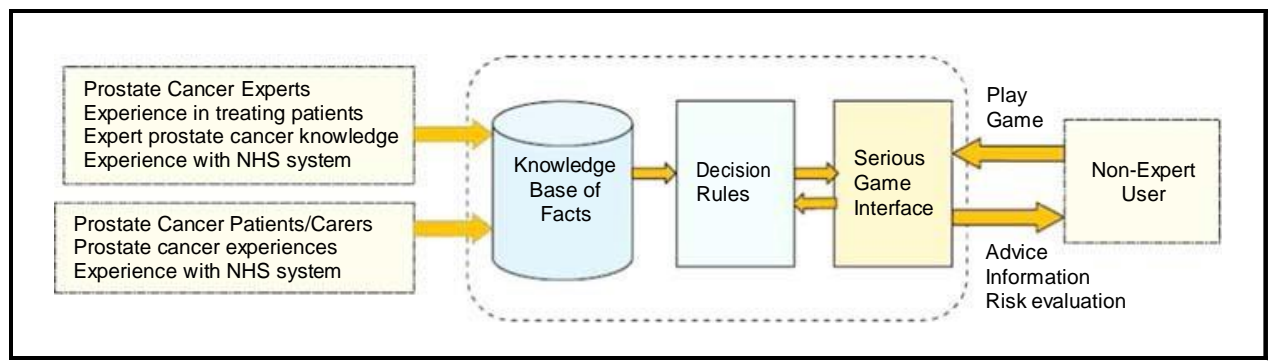

The hybrid Agile-SGDA methodology provided an opportunity to efficiently manage the serious game design and development stages when users were largely involved in all stages. Importantly, theAgilemethodologyisadaptableto change, which madeitsuitablefortheserious gameproject. When a product is being developed it is very likely that changes will occur based on new information, and thus the Agile methodology provides guidelines to help manage the changes and to keep a project under control. The Agile methodology (Beck et al., 2001) states that we value:

- individuals and interactions over processes and tools;

- working software over comprehensive documentation;

- customercollaboration over contractnegotiation; and

- responding to change over following a plan.

The stages of the Agile-SGDA methodology were applied to the design and development of the PROCEE serious game, as follows (Millard et al., 2009):

1. Stakeholder analysis: the stakeholders of the system are:

- Primary stakeholders: these are the people who use the serious gamedirectly. These are men who use the game to receive first-hand information, or partners/family/friends who wish to obtain information and pass it on to others.

- Secondary stakeholders: people who do not use the system directly, but receive output from it or provide input to it (indirect users). These are the prostate cancer experts, and psychologists, clinical commissioning group members, community leaders, and others with insight into prostate cancer.

- Tertiary stakeholders: people who do not interact with the system either directly or indirectly, but who are affected by its success (or failure). These are the General Practitioners, nurses, and NHS clinics who will be able to receive patients with prostate cancer symptoms and treat them earlier.

- Facilitating stakeholders: this category includes researchers, computer scientists (programmers and systems analysis), the project manager, the principal investigator of the project, graphic designers, actors/directors, and all other people who were involved with the design, development and maintenance of the system.

2. Shared problem understanding: in order to gather the exact requirements and ensure that there was a common understanding among researchers and potential game users of the problem to be addressed, a set of interviews and focus groups were conducted. During interviews, the researchers and participants discussed as-is scenarios, and during focus groups, the technology show-and-tell approach was adopted where there was a discussion on how technology can be used to deliver software that meets their expectations.

3. Design: during the design phase, a set of to-be scenarios and possible narratives were discussed with participants. Game versions were developed and shown to participants during focus groups and user feedback sessions. Each version was updated to include extra functionality based on user feedback and the documentation was maintained. Testing and user acceptance took place at the end of each iteration. 
4. Developmentandfeedback: afterthelastiteration, theseriousgamewasthoroughlytested by the developers, and during testing sessions with participants. The think-aloud approach was adopted. For which each participant was asked to use the game and "think aloud" (i.e. speak his thoughts) about the game both in terms of functionality and usability. This feedback was used to make the final changes to the game, which were then approved before release.

\section{PROCEE focus group evaluations}

Oncethe initial software prototype was developed, a workshop was organised specifically for the targetaudience to providefeedbackaboutthe prototype. African-Caribbean men wereinvited to participate at the workshop. The workshop included activities for participants to test and to provide feedback about the PROCEE serious game. The feedback was thereafter effectively utilised to improve the game.

The workshop was attended by 29 participants, fiveorganisers, members of the public, prostate cancer experts and researchers. The participants were found via African-Caribbean community group leaders and members, who were also active members of the project's steering group committee. During the focus group evaluations, the serious game prototype was installed on 20 tablets and each participant was given the opportunity to use the tablets to play the game from start to finish. Onceall participants had used the game, they were placed into small focus groups, and were encouraged to provide feedback and suggestions for changes and additional functionality which could enhance the games quality and usability. One researcher was assigned to each focus group in order to lead the discussion and to record the participants' experiences of using the game. Hence, during the workshop session, all participants were presented with a set of questions which were designed to encourage discussion among the participants and the researchers. The questions were concerned with design, usability, functionality (e.g. existing game functionality and desired game functionality) and impact on user behaviour.

Participants were asked the following questions during the workshop session. These questions were purposely designed to be open-ended questions in order to encourage discussion among the participants and the researchers:

1. Would you use the game?

2. What changes would you make to the game?

3. Would you add other game settings? What would these settings be?

4. Would you add more characters? Are the voices ok, should the voices be louder or quieter?

5. What would make the game easier to use? (how easy is it to use the buttons to control the game? is it easy to start?)

6. What would you like to add to the serious game?

7. Has the game raised your awareness of prostate cancer symptoms?

8. Are you more likely to see a doctor if you experience prostate cancer symptoms?

9. Can you think of a good name for the game? (there is a prize for the best suggestion!)

All the feedback was then considered to create the final version of the PROCEE serious game. The feedback gathered from the workshop and the focus groups revealed common consensus that the PROCEE serious game is very useful in raising awareness of prostate cancer among the African-Caribbean community. The participants embraced the fact that the application was designed by the community for the community. They stated that the game is very likely to encourage symptomatic African-Caribbean men to seek medical attention in a timely manner. After using the application, participants acknowledged that they were more aware about prostate cancer symptoms and tests, they were more likely to recognise the symptoms; and would arrange to see their doctor if they experience symptoms in the future. Participants emphasised that the standardised "IPSS" questionnaire which was integrated into the application was very beneficial, given that the feedback provided from the test clearly determines whether a user should visit their doctor based on their symptoms. The participants 
also stated that the serious game is very effective in educating about the various tests (without information overload). Furthermore, there was common agreement amongst the participants that the serious game addresses the concerns of African-Caribbean men have about the DRE test, which is a barrier preventing men visiting their doctor. During the focus group evaluations, feedback was gathered about the serious game's functionality; and changes that need to be made to the game in order to improve usability and effectiveness in terms of meeting its aim. Users requested some minor changes related to the appearance of the background settings and that more functionality was added with regards to changing the game's settings. The users requested changes to be made to the appearance of certain characters of the game in order to better represent the target audience. In addition, users requested that English subtitles are added to the game to better appeal the younger population. All requests were minor and the game was edited to accommodate these minor changes. Participants requested a major addition to the functionality of the risk prediction layer. They requested that a numerical prediction of their risk is presented to the users. However, this request will take time to be implemented due to the fact that prediction models of such nature need to be appropriately validated with patients prior to being embedded within the serious game. However, to accommodate this requirement, a separate prostate cancer staging prediction tool was designed and implemented. The prediction tool takes as input various clinical test results and predicts the likelihood that the cancer has spread before treatment is given to the patient. Once the tool is clinically evaluated, it will be integrated into the PROCEE serious game. The users felt that their collaboration with the research team resulted in the design and production of a serious games that will benefit the hard to reach community of black African-Caribbean men, and to successfully inform them and their families about prostate cancer.

\section{Discussion, conclusion and future work}

Prostate cancer is the most common cancer diagnosed in men in the UK. Black men and those with have a family history of prostate cancer are in a high risk group. In order to develop culturally sensitive interventions which can effectively enhance knowledge and understanding of prostate cancer in African-Caribbean men, it is important to adopt a co-design approach to software development. Users have participated in the co-design of the proposed PROCEE serious gamethey defined their requirements and were involved from the design to the development stages. PROCEE is an innovative serious gameon prostate cancer which aims to provide African-Caribbean men with information about the disease and also evaluates prostate cancer risk based on their profile and symptoms. The game is particularly useful to those users who are in a higher risk group due to their family history, age, ethnicity or symptoms - it is important to educate high risk men about prostate cancer symptoms so that they are able to recognise symptoms early and seek medical advice in a timely manner. Evaluations of PROCEE revealed that the users enjoyed playing the game, and the users emphasised that it is likely that the game will have great impact on changing the behaviour of symptomatic men by encouraging them to seek medical attention in a timely manner. The game is an effective intervention for raising awareness, among African-Caribbean men, of prostate cancer risks and symptoms. Current work involves developing state of the art risk prediction models for predicting prostate cancer. Future work includes enhancing the virtual environment background; adding more information aboutcoping with prostate cancer; and also adding information about how to improve health habits which could impact on prostate cancer risk. The PROCEE serious game is freely available to everyone for download and use on their own devices.

\section{References}

Alamri, A., Hassan, M.M., Hossain, M.A., Al-Qurishi, M., Aldukhayyil, Y. and Hossain, M.S.(2014), "Evaluating the impact of a cloud-based serious game on obese people", Computers in Human Behavior, Vol. 30, pp. 468-75.

Al-Smadi, M., Wesiak, G. and Guetl, C. (2012), "Assessment in serious games: an enhanced approach for integrated assessment forms and feedback to support guided learning", 15th International Conference on Interactive Collaborative Learning (ICL), IEEE, pp. 1-6. 
Beck, K., Beedle, M., van Bennekum, A., Cockburn, A., Cunningham, W., Fowler, M., Grenning, J., Highsmith, J., Hunt, A., Jeffries, R., Kern, J., Marick, B., Martin, R.C., Mellor, S., Schwaber, K., Sutherland, J. and Thomas, D. (2001), "Manifesto for agile software development", available at: www.agilemanifesto.org/

Bunker, C., Patrick, A., Konety, B., Dhir, R., Brufsky, A., Vivas, C., Becich, M., Trump, D. and Kuller, L. (2002), "High prevalence of screening-detected prostate cancer among afro-caribbeans: the tobago prostatecancer survey", Cancer Epidemiology Biomarkers and Prevention, Vol. 11 No. 8, pp. 726-9.

Burford, D., Kirby, M. and Austoker, J. (2009), "Prostatecancer riskmanagementprogramme: informationfor primary care PSA testing in asymptomatic men.

Center, M.M.,Jemal, A., Lortet-Tieulent, J., Ward,E., Ferlay, J., Brawley, O.andBray, F. (2012), "International variation in prostate cancer incidence and mortality rates”, European Urology, Vol. 61 No. 6, pp. 1079-92.

Danielsson, K. and Wiberg, C. (2006), "Participatory design of learning media: designing educational computer games with and for teenagers", Interactive Technology and Smart Education, Vol. 3 No. 4, pp. 275-91.

Davis, M.A., Quittner, A.L., Stack, C.M. and Yang, M.C. (2004), "Controlled evaluation of the starbright cd-rom program for children and adolescents with cystic fibrosis", Journal of Pediatric Psychology, Vol. 29 No. 4, pp. 259-67.

Diehl, L.A., Souza, R.M., Alves, J.B., Gordan, P.A., Esteves, R.Z., Jorge, M.L.S.G. and Coelho, I.C.M. (2013), "Insuonline, a serious game to teach insulin therapy to primary care physicians: design of the game and a randomized controlled trial for educational validation", JMIRResearch Protocols, Vol. 2 No. 1.

Fuchslocher, A., Niesenhaus, J. and Krämer, N. (2011), "Serious games for health: an empirical study of the game balance for teenagers with diabetes mellitus", Entertainment Computing, Vol. 2 No. 2, pp. 97-101.

Glover, F., Coffey, D., Douglas, L., Cadogan, M., Russell, H., Tulloch, T., Baker, T., Wan, R. and Walsh, P. (1998), "The epidemiology of prostate cancer in jamaica”, Journal of Urology, Vol. 159 No. 6, pp. 1984-7.

Heijnsdijk, E., Wever, E. and deKoning, H. (2012), "Cost-effectiveness of prostatecancer screening based on the european randomised study of screening for prostate cancer", The Journal of Urology, Vol. 187 No. S4, p. e491.

Kato, P.M., Cole, S.W., Bradlyn, A.S. and Pollock, B.H. (2008), "A video game improves behavioral outcomes in adolescents and young adults with cancer: a randomized trial”, Pediatrics, Vol. 122 No. 2, pp. e305-e317.

Khaled, R. (2012), "Muse-based game design", Proceedings of the Designing Interactive Systems Conference, $A C M$, pp. 721-30.

Lange-Nielsen, F., Lafont, X.V., Cassar, B. and Khaled, R. (2012), "Involving players earlier inthegamedesign process using cultural probes", Proceedings of the 4th International Conference on Fun and Games, ACM, pp. 45-54.

Lieberman, D.A. (2001), "Management of chronic pediatric diseases with interactive health games: theory and research findings", The Journal of ambulatory care management, Vol. 24 No. 1, pp. 26-38.

Luján, M., Páez, À., Berenguer, A. and Rodríguez, J. (2012), "Mortality due to prostate cancer in the spanish arm of the european randomized study of screening for prostate cancer (ERSPC). Results after a 15-year follow-up", Actas Urológicas Españolas (English Edition), Vol. 36 No. 7, pp. 403-9.

Millard, D., Howard, Y., Gilbert, L. and Wills, G. (2009), "Co-design and co-deployment methodologies for innovative m-learning systems", Multiplatform E-Learning Systems and Technologies: Mobile Devices for Ubiquitous ICT-Based Education, IGI Global.

Mitgutsch, K. and Alvarado, N. (2012), "Purposeful by design?: a serious game design assessment framework", Proceedings of the International Conference on the Foundations of Digital Games, ACM, New York, NY, pp. 121-8.

Ream, E., Pedersen, V. and Armes, J. (2010), "Perceptions of prostate cancer and prostate cancer risk in men of African Caribbean descent: a systematic review", European Journal of Oncology Nursing, Vol. 14 No. S1, p. S50.

Reichlin, L., Mani, N., McArthur, K., Harris, A.M., Rajan, N. and Dacso, C.C. (2011a), "Assessing the acceptability and usability of an interactive serious game in aiding treatment decisions for patients with localized prostate cancer", Journal of Medical Internet Research, Vol. 13 No. 1. 
Reichlin, L., Mani, N., McArthur, K., Harris, M.A., Rajan, N. and Dacso, C.C. (2011b), "Assessing the acceptability and usability of an interactive serious game in aiding treatment decisions for patients with localized prostate cancer", Journal of Medical Internet Research, Vol. 13 No. 1.

Saposnik, G., Teasell, R., Mamdani, M., Hall, J., McIlroy, W., Cheung, D., Thorpe, K.E., Cohen, L.G., Bayley, M. et al. (2010), "Effectiveness of virtual reality using wii gaming technology in stroke rehabilitation a pilot randomized clinical trial and proof of principle", Stroke, Vol. 41 No. 7, pp. 1477-84.

Schönauer, C., Pintaric, T. and Kaufmann, H. (2011), "Full body interaction for serious games in motor rehabilitation", Proceedings of the 2nd Augmented Human InternationalConference, ACM, p. 4.

Schröder, F.H., Hugosson, J., Carlsson, S., Tammela, T., Määttänen, L., Auvinen, A., Kwiatkowski, M., Recker, F. and Roobol, M.J. (2012), "Screening for prostate cancer decreases the risk of developing metastatic disease: findings from the european randomized study of screening for prostatecancer(ERSPC)", European Urology, Vol. 62 No. 5, pp. 745-52.

Siegel, R., Ward, E., Brawley, O. and Jemal, A. (2011), "Cancer statistics, 2011: the impact of eliminating socioeconomic and racial disparities on premature cancer deaths", CA Cancer Journal for Clinicians, Vol. 61 No. 4, pp. 212-36.

Stokes, B. (2005), "Videogames have changed: time to considerserious games'?", Development Education Journal, Vol. 11 No. 3, p. 12.

Thompson, D., Baranowski, T., Buday, R., Baranowski, J., Thompson, V., Jago, R. and Griffith, M.J. (2008), "Serious video games for health: how behavioral science guided the design of a game on diabetes and obesity", Simulation \& Gaming.

Vines, J., Clarke, R., Wright, P., McCarthy, J. and Olivier, P. (2013), "Configuring participation: on how we involvepeopleindesign", Proceedings of the SIGCHIConference on Human Factors in Computing Systems, ACM, pp. 429-38.

Wattanasoontorn, V., Boada, I., Garca, R. and Sbert, M. (2013), "Serious games for health", Entertainment Computing, Vol. 4 No. 4, pp. 231-47.

Winn, B. (2008), "The design, play, and experience framework", Handbook of Research on Effective Electronic Gaming in Education, Vol. 3, pp. 1010-24.

\section{Authors bibliography}

Georgina Cosma is a Senior Lecturer, David Brown is a Professor of Interactive Systems for Social Inclusion, Nicholas Shopland is a Research Fellow and Steven Battersby is a Research Fellow, all at the Department of Computing and Technology, School of Science and Technology, Nottingham Trent University, Nottingham, UK.

Sarah Seymour-Smith is a Senior Lecturer at the College of Business Law and Social Sciences, School of Social Sciences, Nottingham Trent University, Nottingham, UK.

Matthew Archer is a Placement Researcher at the Department of Computing and Technology, School of Science and Technology, Nottingham Trent University, Nottingham, UK.

Masood Khan is a Consultant Urological Surgeon at the Department of Urology, University Hospitals of Leicester NHS Trust, Leicester, UK.

A. Graham Pockley is an Associate Director and a Professor of Immunobiology at the John van Geest Cancer Research Centre, Nottingham Trent University, Nottingham, UK. 